\title{
PROPIEDAD RURAL Y PROPIEDAD URBANA. REFLEXIONES SOBRE LAS PREFERENCIAS INVERSORAS DE LOS RENTISTAS VALENCIANOS DEL SIGLO XVIII Y OTRAS CAUSAS
}

\author{
Por Fernando ANDRÉS ROBRES. 1987
}

En un reciente trabajo intenté acercarme al problema de la renta urbana en la Valencia del setecientos, examinando el comportamiento de algunas series de precios de arrendamientos de casas sitas en la ciudad (1). El tema, inédito hasta entonces, se justificaba en sí mismo suficientemente. No obstante, los objetivos últimos por los que fue abordado superaban el marco del análisis cuantitativo de la evolución de la coyuntura económica: aquella investigación tenía también sentido como paso obligado en el planteamiento de cuestiones que considero tanto o incluso más interesantes.

Es ya un hecho conocido que, durante el siglo XVIII, buena parte de los rentistas valencianos, laicos y eclesiásticos, cambian sus objetivos de inversión y con ello sus fuentes de ingresos: de un crédito a gran escala que entra en crisis a la propiedad inmueble (2). Gran cantidad de haciendas, mayores y menores, se vieron así reconvertidas. El fenómeno ha llamado la atención, sobre todo, en sus efectos sobre la distribución social de la propiedad de la tierra, analizándose siempre desde una perspectiva agraria. Es algo bien lógico: con seguridad, la tierra absorbió la mayor parte de la inversión inmobiliaria. Simplemente pretendemos ahora ir un poco más allá, sosteniendo como hipótesis que también la dimensión urbana de las transformaciones pudo ser importante, desarrollándose además, muy probablemente, en estrecha relación con la rural.

Esa impresión derivaba del estudio de la evolución patrimonial y rentista del Real Colegio de Corpus Christi. La institución fundada por el Patriarca Ribera ejemplifica a la perfección el tránsito crédito-propiedad al que aludíamos, como ya hemos puesto de manifiesto en otros lugares ${ }^{(3)}$ y como puede comprobarse desde la lectura del Cuadro 1. Da cuenta la tabla de la evolución de los ingresos patrimoniales reales de la fundación en cuatro cortes entre 1691-1700 y 1841-1850, distribuidos en los que eran sus cuatro principales apoyos rentistas: los préstamos censales, la explotación de los señoríos de Alfara y Burjassot —en la que la ma- 


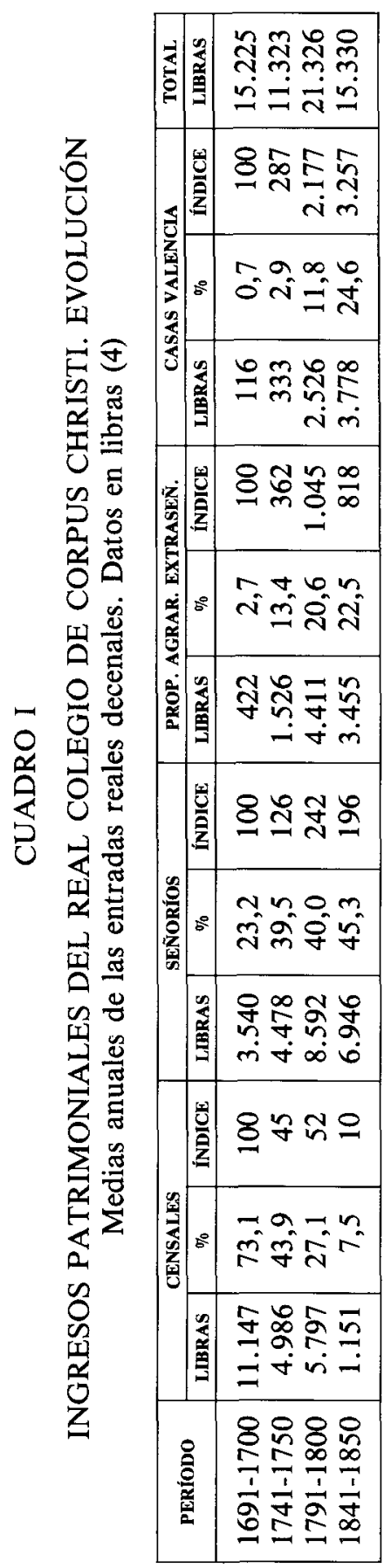


yor parte del ingreso procede del arrendamiento de tierras que el Colegio detenta como propietario tras una intensa amortización-, el también arriendo de tierras ubicadas fuera de sus lugares y, finalmente, el alquiler de casas sitas en la ciudad de Valencia.

Poco hay que explicar. Defenestrado el crédito censal ya en la primera mitad del siglo XVIII, lo que costará al Colegio la súbita pérdita del 50 por 100 de sus rentas y, progresivamente, los ingresos procedentes de la propiedad inmueble, en la que se realizan fuertes inversiones, van ganando importancia en términos absolutos y, sobre todo, relativos. Y no es difícil precisar un poco más: en primera instancia, la responsabilidad de la recuperación del ingreso global recae en la propiedad agraria, incluidos señoríos; las 333 libras ingresadas por casas y como media en la década 1741-50, cantidad aún casi despreciable, así lo indica. Pero la progresión de la renta urbana es ya espectacular, la más importante relativamente, en la segunda mitad del siglo XVIII. Y, lo que es menos sorprendente, su tendencia al alza va a continuar en el ochocientos, cuando todos y cada uno de los restantes capítulos de la hacienda reducen sus aportaciones, llevando otra vez en descenso al conjunto de la renta patrimonial de la Fundación ${ }^{(5)}$.

\section{CUADRO II}

EVOLUCIÓN DEL PATRIMONIO Y LA RENTA URBANA DEL R.C.C.C. S. XVIII-XIX (6)

\begin{tabular}{|c|c|c|c|c|}
\hline DÉCADA & $\begin{array}{c}\text { NÚMERO } \\
\text { ALQUILERES } \\
\text { AÑO FINAL }\end{array}$ & $\begin{array}{c}\text { RENTA TEÓRICA } \\
\text { AÑO FINAL } \\
\text { (LIBRAS) }\end{array}$ & $\begin{array}{c}\text { INGRESOS } \\
\text { REALES MEDIOS } \\
\text { (LIBRAS) }\end{array}$ & $\begin{array}{c}\% \text { SOBRE TOTAL } \\
\text { INGRESO } \\
\text { PATRIMONIO REAL }\end{array}$ \\
\hline $1691-1700$ & 12 & 104 & 116 & $1 \%$ \\
$1701-1710$ & 12 & 135 & 106 & $1 \%$ \\
$1711-1720$ & 13 & 216 & 153 & $1 \%$ \\
$1721-1730$ & 12 & 231 & 214 & $1 \%$ \\
$1731-1740$ & 12 & 239 & 237 & $2 \%$ \\
$1741-1750$ & 15 & 307 & 333 & $3 \%$ \\
$1751-1760$ & 20 & 438 & 374 & $3 \%$ \\
$1761-1770$ & 34 & 1.109 & 821 & $5 \%$ \\
$1771-1780$ & 60 & 1.774 & 1.379 & $8 \%$ \\
$1781-1790$ & 57 & 2.150 & 1.739 & $9 \%$ \\
$1791-1800$ & 61 & 3.124 & 2.526 & $12 \%$ \\
$1801-1810$ & 53 & 2.891 & 2.821 & $15 \%$ \\
$1811-1820$ & 53 & 3.219 & 2.417 & $18 \%$ \\
$1821-1830$ & 53 & 3.461 & 2.876 & $21 \%$ \\
$1831-1840$ & 63 & 3.639 & 3.417 & $23 \%$ \\
$1841-1850$ & 64 & 3.880 & 3.778 & $25 \%$ \\
$1851-1860$ & 66 & 4.686 & 4.225 & $25 \%$ \\
$1861-1870$ & 39 & 2.582 & 4.953 & $28 \%$ \\
\hline
\end{tabular}


En el Cuadro 2 exponemos con mayor precisión los datos correspondientes a la evolución de la renta urbana del Colegio. Década a década se ofrece la siguiente información: número de viviendas alquiladas y renta teórica que generan en el último año de cada decenio, e ingresos reales anuales medios y porcentaje que esos ingresos suponen sobre el conjunto de la renta patrimonial efectiva de la Institución. El contraste entre rentas teóricas y realmente cobradas, aunque solo aproximado, nos será útil más adelante para evaluar la efectividad de la renta.

Su lectura permite fijar con exactitud la cronología del desarrollo de este apartado de la hacienda. Queda de manifiesto la intensidad de una progresión que, insitimos, comienza con retraso respecto a la de las tierras, afirmándose sólo en la década 1761-70 - quizá tímidamente unos años antes-, pero para mostrarse después imparable; casi se cuadruplican los ingresos entre esas fechas y el final de la centuria, creciendo en términos absolutos en la segunda mitad del XVIII - ver Cuadro 1 - tanto como la renta de la propiedad agraria extraseñorial. Después, la desamortización de Godoy afecta a algunas de las casas ${ }^{(7)}$, con lo que la década 1811-1820 acusa un pequeño bache. Pero la recuperación es rápida, prosiguiendo el crecimiento durante el XIX y hasta la desamortización final, que sólo afecta al Colegio en la década $1861-70^{(8)}$; el alza ya no es ahora tan intensa - salvo excepciones que inducen a pensar en anomalías ${ }^{(9)}$ - como lo fue en las últimas dećadas del siglo anterior, expecialmente en términos relativos. Pero continúa constante. Y el progreso es aún más significativo en relación a las restantes fuentes de ingresos, como expresa el cálculo que muestra su contribución a la renta patrimonial global de la Fundación; el arrendamiento de casas aporta, mediado el ochocientos, nada menos que un 25 por 100 , contra el 12 por 100 de 1800 y el 3 por 100 de 1750 .

Así las cosas, parecía claro que el interés por los inmuebles urbanos comenzaba a competir con la dedicación agraria desde aproximadamente el último tercio del XVIII, cuando antes apenas se había tenido en cuenta. Y que llegaba a superarla netamente en el XIX, en que, como ya hemos expuesto en otra parte, las únicas inversiones del Colegio son, aunque no muy elevadas, casi íntegramente dedicadas a viviendas en la ciudad de Valencia ${ }^{(10)}$. Debían hallarse causas que pudieran explicar esa evolución, que raramente obedecería a circunstancias extraeconómicas: sabíamos de la atención con que los responsables del Colegio actuaban en todas las cuestiones que atañían a la conservación y mejora de su hacienda ${ }^{(11)}$.

Para proyectar alguna luz sobre los problemas, una de las pocas posibilidades a nuestro alcance consistía en realizar un estudio comparativo de evolución de las cotizaciones de arrendamientos agrarios y urbanos durante el período objeto de análisis. Ese contraste se representa gráficamente en la Figura n. ${ }^{\circ} 1$, cuyo contenido explicamos brevemente: procede la curva de arrendamientos agrarios de parcelas de tierra huerta sitas en el lugar de Burjassot, inmediato al término de la capital ${ }^{(12)}$. Y dibujamos dos curvas diferentes referidas a arriendos urbanos, representativas de las dos muestras más homogéneas que hemos podido elaborar en nuestro ya citado estudio sobre evolución de la renta urbana; procede una de arrendamientos de casas propiedad del Colegio del Patriarca, y la segunda 
de viviendas administradas por la parroquia de San Miguel ${ }^{(13)}$. El trazado de una cuarta curva reflejo de la evolución de los precios del trigo en Valencia, sirve de referencia común ${ }^{(14)}$. Por último, y para hacer posibles las comparaciones, todas las series han sido reducidas a índices, con período base en 1731-40.

El análisis de las distintas evoluciones ofrece algunas informaciones de interés, si bien es seguro no resuelve todos nuestros interrogantes. Es claro que todos los indicadores coyunturales reflejados dibujan un siglo XVIII netamente alcista cuando menos desde la década de 1730, quizá ya desde antes - 1715 ó 1720en el caso de los alquileres de viviendas. Matizando algo más, el crecimiento parece intenso en el período $1740-1770 / 75$ para los arriendos agrarios y urbanos, que dejan atrás entonces a los precios del grano. Después, y en un comportamiento que ya había sido observado con anterioridad, el alza se ralentiza entre los años 70 y 90 , para volver a afirmarse en la década final de la centuria; aunque no con la decisión necesaria para contrarrestar en esos años a unos precios del trigo que ahora se disparan.

Centrándonos en la comparación que aquí nos interesa de forma especial, una reflexión básica: a tenor de los resultados de nuestras muestras no podemos establecer jerarquías en las alzas experimentadas por los indicadores principales, precios de arrendamientos agrarios y precios de arrendamientos urbanos, durante el siglo XVIII. Y es que la curva de arriendo de tierras se sitúa en su crecimiento, precisamente, en un nivel intermedio entre las dos correspondientes a cesiones de casas: con un 120,3 por 100 de incremento - cálculo en 1801-10 respecto de 1731-10 - , supera el alcanzado por las viviendas del Colegio $(92,4$ por 100$)$, pero queda por debajo de las de San Miguel (127,7 por 100). Debemos además añadir que aun en el caso de que los resultados se hubieran mostrado en apariencia más fáciles de interpretar, en uno u otro sentido, habríamos igualmente renunciado a pronunciarnos con rotundidad al respecto. Porque si alguna característica define el comportamiento de los arriendos urbanos, esa es la irregularidad; irregularidad que, patente como vemos en las diferencias entre distintas muestras, afecta también en ocasiones a las series individuales que las integran, pese a nutrirse aquéllas de propiedades suficientemente homogéneas en apariencia ${ }^{(15)}$.

Por lo demás, sí podemos en cambio deducir desde la misma figura otra significativa apreciación: los arrendamientos urbanos continúan cotizándose al alza, al menos, entre 1810 y 1830 , pudiendo justificar así, siempre en apreciación provisional y aunque sólo parcialmente, tanto que se siga invirtiendo en casas en el XIX, como que, aunadas inversión y progresión rentista, la propiedad urbana del Colegio continúe experimentando alzas en sus rendimientos durante el nuevo siglo ${ }^{(16)}$.

Pero en definitiva, y por lo que hace a la fase que pretendemos analizar especialmente, sólo podemos que esbozar una impresión muy general: al parecer, quienes están invirtiendo en casas durante la segunda mitad del XVIII, o quienes lo hubieran hecho ya con anterioridad, no hacen peor negocio desde el punto de vista de la evolución rentista que aquéllos que optan por las tierras.

Es esa una conclusión que nos resulta insuficiente, no obstante, a la vista, como posible ejemplo representativo, de la evolución patrimonial y rentista del 
Real Colegio; desde la perspectiva, insistimos, de lo que parece una súbita atracción por la propiedad urbana, despreciada prácticamente hasta 1760 y potenciada a partir de esa fecha en proporción superior a cualquier otro apoyo rentista. $Y$ es que, además, noticias de otras procedencias tienden a afirmarnos en la idea de que la propiedad urbana es especialmente apetecida $-o$, simplemente, sobreutilizada ante hipotéticos problemas de fuentes de ingresos distintas-, por los sectores sociales rentistas desde el último tercio del siglo XVIII y, al menos, durante algunas décadas en adelante. Veamos en qué consisten esas noticias.

Con la intención de encontrar contabilidades en que fuera factible la elaboración de series de arrendamientos urbanos, consultamos buena parte de la sección de Clero del Archivo del Reino de Valencia, repasando fondos pertenecientes a 30 diferentes instituciones: 9 parroquias, 18 conventos y 3 colegios eclesiásticos ${ }^{(17)}$. Limitándonos exclusivamente a aquéllas con información aprovechable, la lista quedó reducida a cinco: cuatro cenobios - Carmen, Merced, Santo Domingo y Santa Úrsula-, y la ya citada parroquia de San Miguel. En esos casos, la posibilidad de seguir en series más o menos largas o en cortes la evolución de los precios de cesión de determinadas casas, permitía también, es lógico, observar las alteraciones sufridas por los respectivos patrimonios urbanos.

Pues bien. Sólo en uno de los ejemplos, concretamente el Convento del Carmen, el número de alquileres no se incrementaba entre las fechas límite encuestadas, concretamente 1782 y 1816 , permaneciendo estable en torno a $33^{(18)}$. Las cuatro instituciones restantes veían por el contrario aumentar considerablemente el número de viviendas; concretamente, de la forma que resume el Cuadro 3, que da cuenta, además, también, de las progresiones rentistas aproximadas.

Los datos parecen significativos. La administración que regenta la parroquia de San Miguel casi dobla sus alquileres y quintuplica sus rentas urbanas durante el siglo XVIII. La progresión de Santo Domingo es asimismo importante, sobre todo cuando comprobamos el volumen de sus posesiones y el incremento de sus rentas. Y en apenas 37 años, el Convento de la Merced se hace con 17 nuevos alquileres y duplica sus ingresos por ese concepto. Por último, apenas más modesta es la evolución del patrimonio y renta del Convento de Santa Úrsula.

En suma, el arrendamiento de casas se muestra como una actividad aparentemente en auge, pujante, durante el período encuestado. Debe tenerse en cuenta, además, que la muestra de instituciones en que nos basamos, elegida con criterios puramente aleatorios -en función, recordamos, de las características de la documentación conservada-, bien pudiera ser representativa de la evolución patrimonial urbana de la mayor parte de las haciendas eclesiásticas de la ciudad de Valencia. El ejemplo del Real Colegio aboga, desde luego, por las mismas conclusiones, potenciándolas en todo caso.

Pero además, quizá tan importante como evaluar el desarrollo de las haciendas, era conocer el modo en que muy habitualmente se llevan a cabo las ampliaciones, algo que, pensamos, puede ofrecernos interesantes pistas en el intento de responder a los interrogantes que planteamos. Por supuesto que, al margen de las donaciones, una de las posibles vías para ampliar los patrimonios es la compra. Pero no lo única. Ni siquiera parece la más frecuentemente utilizada. Ese 
A. Administración del Dr. D. Francisco Espejo. Parroquia de San Miguel

\begin{tabular}{|c|c|c|c|}
\hline AÑo & NÚMERo DE ALQUILERES & RENTA ANUAL LIBRAS & INDICE \\
\hline 1729 & 8 & 71,5 & 100 \\
1809 & 14 & 348,5 & 487 \\
\hline
\end{tabular}

B. Convento de Santo Domingo

\begin{tabular}{|c|c|c|c|}
\hline AÑo & NÚMERO DE ALQUILERES & RENTA ANUAL LIRRAS & INDICE \\
\hline 1758 & 153 & 2.892 & 100 \\
1814 & 193 & 6.359 & 220 \\
\hline
\end{tabular}

C. Convento de Santa Úrsula

\begin{tabular}{|c|c|c|c|}
\hline AÑo & NÚMERO DE ALQUILERES & RENTA ANUAL LIBRAS & INDICE \\
\hline 1765 & 14 & 365,5 & 100 \\
1825 & 21 & 676,0 & 185 \\
\hline
\end{tabular}

D. Convento de la Merced.

\begin{tabular}{|c|c|c|c|}
\hline AÑo & NÚMERo DE ALQUILERES & RENTA ANUAL LIBRAS & INDICE \\
\hline 1785 & 51 & 2.261 & 100 \\
1814 & 68 & 3.448 & 152 \\
1822 & 68 & 4.108 & 182 \\
\hline
\end{tabular}

calificativo debe reservarse, pensamos, para la construcción propia. Los propietarios eclesiásticos incrementan a menudo el número de sus alquileres edificando por cuenta propia determinados solares o, aún más habitualmente, reedificando sobre viejas casas de sus haciendas. Pondremos algunos ejemplos.

El convento de Santa Úrsula lleva a cabo un mínimo de dos reedificaciones. Una casa de la calle de Barcelona, se derribó y reedificó en el año 1791. Importó la obra 2.445 libras, 13 sueldos y 4 dineros, y se dividió en casa baja y tres habitaciones altas... ${ }^{(20)}$. Es decir, de donde se obtenía un alquiler, saldrán ahora cua- 
tro. Y si el antiguo rentaba 24 libras al año, los nuevos cuestan $34,39,35$ y 30 libras, respectivamente, en 1792, un total de 138 libras. La renta se ha multiplicado por 5,5, mediando, claro, una inversión.

Ejemplos parecidos aporta la parroquia de San Miguel que ve arruinadas tres casas de la administración del Dr. Espejo por lluvias caídas en diciembre de 1783. En una de ellas, en la calle Peixcadors, la reedificación comprenderá cuatro estancias, entre ellas un obrador para instalar telares. Y rendirá 102 libras $(20,22$, 20 y 38 ) contra las 18 anteriores, con gasto de 1.289 libras y 3 sueldos. Y más interesante es el caso de las otras dos, contiguas, en la calle del Fumeral. Se ha resuelto la reedificación inmediatamente, pero el experto consultado indica que la obra resultaría más ventajosa si se dispusiese de parte de otra finca lindante. La parroquia gestiona rápidamente su adquisición, aunque para ello debe solicitar dinero a censo, que le es prestado por el Convento de San Felipe. En 1787 arrendará allí cinco viviendas por importe conjunto de 150 libras $(22,22,24,24$ y 58) - antes obtenía 36 (18 y 18)-, tras una inversión de 2.369 libras, 14 sueldos y 1 dinero ${ }^{(21)}$.

Aunque, sin duda, la actividad más intensa en ese sentido entre las instituciones aquí documentadas, es la protagonizada por el Convento de Santo Domingo. La calidad de la información recogida es peor, puesto que no conocemos datos de los gastos ocasionados por las obras, al disponer tan sólo de sendas fotografías del patrimonio en dos fechas concretas, 1758 y 1814. Pero las evidencias abundan. Reedifican los Predicadores, cuando menos, en las calles Sangre, Acequia Podrida, Pellicers, Baño de las Torres, Gracia, Puerta del Real, Engordo, Xerea, Portal de Valldigna, Peixcadors y Fornals. Y adquieren, también entre las mismas fechas, no por debajo de 15 viviendas; todo ello con las consecuencias que se deducen de la lectura del Cuadro $2{ }^{(22)}$.

Al fin, constatar la dedicación constructora de algunos cleros de la ciudad de Valencia en la segunda mitad del siglo XVIII no ha constituido para nosotros una gran sorpresa en cualquier caso. Como ya hemos referido en otras partes, el Real Colegio se integra decididamente entre las instituciones que la practican. Sin ir más lejos, casi la totalidad de su inversión inmueble en el ochocientos se realiza por esa vía ${ }^{(23)}$, remontándose sus construcciones propias a la centuria anterior, y afectando tanto a su patrimonio ${ }^{(24)}$ como al de las fundaciones de obras pías y vitalicios que regenta. Por ejemplo, en 1782, y como administrador de los bienes legados por don Juan Bautista Valladoig, una reforma sobre tres casas ubicadas en la calle Zapatería de los Niños, permite distribuirlas en doce alquileres diferentes, pasando el precio de su cesión conjunta de 225 a 738 libras anuales ${ }^{(25)}$.

el fenómeno resulta así, en apariencia, general, e invita a la reflexión, larga reflexión en la que haremos referencia a un buen número de hipótesis y que hará las veces de conclusión final.

Hemos comprobado mediante una serie de ejemplos que bien pudieran ser representativos la intensa progresión de la propiedad y renta urbanas en las haciendas de algunos rentistas eclesiásticos en la segunda mitad del XVIII. En casos determinados, como el Convento de Santo Domingo, el punto de partida es ya 
considerable; es algo normal, y nada podemos decir al respecto, puesto que.desconocemos el proceso de gestación de su patrimonio. Pero, en general, no cabe duda que es en el período citado cuando observamos un desarrollo mayor. Todas las reedificaciones que hemos documentado tienen lugar entre 1760 y 1820 ; el patrimonio urbano de la fundación administrada por la parroquia de San Miguel ha permanecido estable entre 1708 y 1783, multiplicándose desde ese instante; $y$, desde luego, el ejemplo del Colegio, el que mejor conocemos, es bien claro al respecto, al igual que el de sus fundaciones de obras pías y vitalicios (26).

Mientras, de otro lado, sabemos que las inversiones de los rentistas en la propiedad agraria se remontan en términos generales al inicio de la centuria, consecuencia probable, al menos en parte, de la crisis crediticia con que se abre el siglo (27). Pensamos, pues, ya lo dijimos, que a partir de un momento dado la dedicación a las fincas urbanas comparte protagonismo con la agraria, y hasta tenemos la impresión, basada desde luego en apreciaciones documentadas, de que en casos determinados pudo llegar a superarla, siempre, por supuesto, en términos relativos.

Evidentemente, el análisis de la evolución de los precios de arrendamientos no justifica esa supuesta alteración; aunque a la vista de lo expuesto no descartamos que determinadas propiedades urbanas pudieron ver encarecer el importe de sus cesiones a lo largo del setecientos en proporción superior a lo que lo hace la propiedad agraria, mucho menos podemos asegurarlo, nunca como norma general.

Pero la explicación bien podría estar en otro tipo de aspectos, algunos relacionados entre sí: pensamos concretamente en la situación del mercado de la tierra, en los rendimientos a plazo corto de las inversiones y en la efectividad de las rentas, la cobrabilidad.

Este último es el argumento de menor peso, contrastado además únicamente en el caso del Real Colegio. Pero de la contabilidad de esa institución se deduce con claridad que de entre todas las fuentes de ingresos que disfruta, la de los alquileres de casas en Valencia es la que cobra con mayor regularidad y prontitud; en el Cuadro 1 hemos of recido datos que corroboran esa excelente cobrabilidad ${ }^{(28)}$. $Y$ en otro lugar puede comprobarse el inferior índice de efectividad de sus restantes rentas ${ }^{(29)}$. Acaso en la base de ese comportamiento se encuentre la proximidad del acreedor al deudor. Aunque, de otro lado, y como es comprensible, tampoco hay que descartar, como en ninguna otra renta, la presencia de serias acumulaciones de impagos en casos determinados, especialmente en coyunturas difíciles y que normalmente conducen al deshaucio ${ }^{(30)}$.

Pasamos, pues, con rapidez a las hipótesis que consideramos más interesantes y verosímiles. En un trabajo de mayor entidad hemos descrito, creemos que con cierto detalle, el comportamiento del mercado de la tierra en la huerta de Valencia de los siglos XVII y XVIII ${ }^{(31)}$. La penetración de los sectores sociales privilegiados como propietarios agrarios, discreta si existe en el seiscientos, es muy intensa desde la Guerra de Sucesión, en un marco ya restringido estructuralmente por los problemas de amortización y vinculación que, es lógico, se agravan conforme avanza la centuria. Continúan sin embargo afluyendo capitales para los que, aparentemente, no existen empleos alternativos suficientemente atractivos, 
y la penetración se convierte así, paulatinamente, en un proceso eminentemente especulativo. Como consecuencia, el precio de la tierra se encarece desmesuradamente, y hasta aparecen algunos fenómenos de reciclaje que nos parecen significativos en relación al problema que aquí tratamos específicamente: el proceso, por ejemplo, centrado en una primera fase exclusivamente en las tierras de calidad, las huertas, comienza a afectar en la segunda mitad de siglo a los secanos... y, también, a la propiedad urbana de los núcleos rurales ${ }^{(32)}$.

$\mathrm{Si}$ afecta a ese tipo de propiedad, tanto más lo haría, es algo del todo lógico, a la propiedad urbana en la ciudad donde residen mayoritariamente los responsables de la penetración, los inversores. En ese sentido, como ya antes habíamos sugerido ${ }^{(33)}$, y como explicación al menos parcial, la inversión en viviendas se justificaría como alternativa y sustitutiva de la inversión agraria, ante un mercado de la tierra limitado, enrarecido y caro.

Y, además, eso podría no ser todo. El encarecimiento de la propiedad agraria, superior proporcionalmente a la elevación de su propia renta expresada en términos de arrendamientos de tierras, conduce a un progresivo deterioro de la rentabilidad que es posible obtener por el procedimiento de adquirir una propiedad y cederla para su explotación arrendándola. Y, desde 1760 aproximadamente, las adquisiciones de tierras próximas a la ciudad arrojan cocientes al respecto nunca superiores al 3,5 por 100 anual y en descenso, situándose probablemente a finales del siglo por debajo del 3 por $100^{(34)}$. No podemos aquí, desde luego, pronunciarnos con datos suficientes y fiables sobre la rentabilidad inmediata que es posible obtener de la inversión urbana. Pero tampoco hay duda que, como probable explicación a los comportamientos observados, la idea de unos rendimientos acaso superiores aflora necesariamente; sobre todo cuando hemos sabido de la forma en que a menudo se realiza esa inversión: por cuenta propia. Para adquirir una propiedad agraria, cualquier comprador debe someterse a las leyes, y por tanto a los precios, del mercado de la tierra. Mientras, en ocasiones, mejorar y ampliar inmuebles urbanos resulta relativamente fácil realizando simplemente algunas obras. Muy probablemente nunca faltará demanda de arriendos en un período de crecimiento demográfico y, sobre todo, urbano. $\mathrm{Y}$ el coste de las obras estará sólo determinado por un mercado bien distinto.

Antes hemos ofrecido algunos ejemplos en que conocemos el importe de determinadas obras y sus consecuencias inmediatas sobre las rentas. Son, es verdad, escasos, pero parecen lo suficientemente precisos como para realizar con ellos algunos cálculos indicativos. El método consiste, sencillamente, en obtener la rentabilidad de cada inversión a partir del coste de las mejoras y el precio del posterior arriendo; deduciendo de este último, desde luego, el valor del arrendamiento que se pagaba antes de la obra, cantidad que de algún modo viene a representar el rendimiento de un solar que, es claro, también tiene su precio. Los resultados, es cierto, no arrojan saldos espectaculares: La inversión del Convento de Santa Úrsula en su casa de la calle Barcelona le reportaría un 4,66 por 100 anual. Y la parroquia de San Miguel obtendría el 4,81 por 100 y el 6,51 por 100 en sus obras de las calles Fumeral y Peixcadors, respectivamente ${ }^{(35)}$. Pero el rendimiento parece superior, con todo, al que hacia esa mismas fechas - todas las obras tie- 


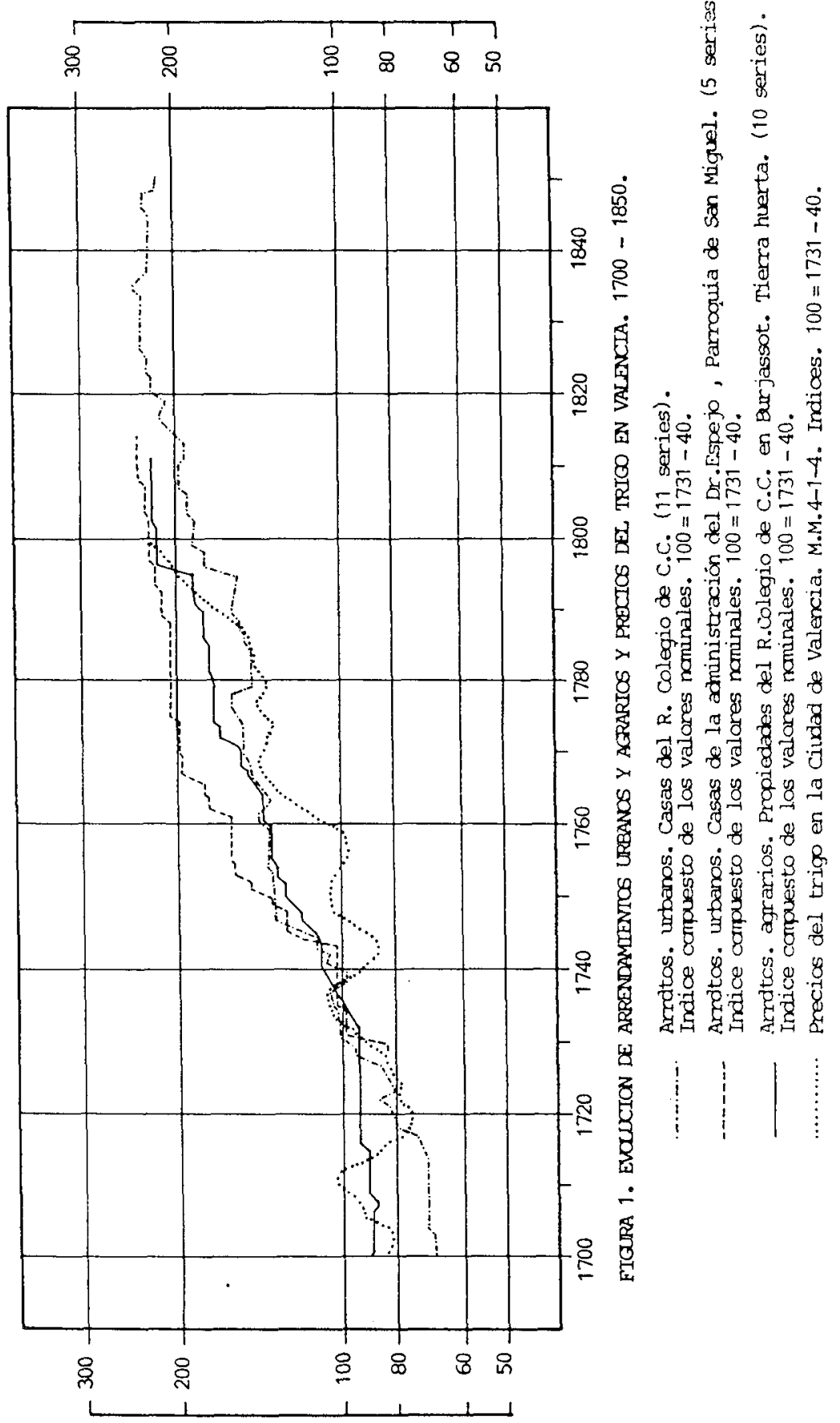


nen lugar entre 1783 y 1791 - era presumible obtener de la inversión en tierras. Los cocientes muestran además suficiente coherencia con una última noticia puntual que aporta nuestra documentación y que ofrecemos a título meramente informativo. Las mismas religiosas de Santa Úrsula adquieren en 1766 una casa en la calle de Serranos. El importe abonado se elevó a 1.201 libras y 10 sueldos, alquilándose a continuación en 50 libras anuales. Rentabilidad, pues, del 4,16 por $100{ }^{(36)}$, incluso lógica por inferior al tratarse de compra y no de obra. Pero, seguramente, en esos niveles se encontraba el rendimiento de la inversión urbana en la Valencia del último tercio del XVIII.

No podemos pretender por el momento que nuestra argumentación traspase el umbral de simple hipótesis. Los datos aportados son aún insuficientes, y habrá que continuar recabando otros nuevos y más completos. Pero pensamos que las teorías ahora expuestas bien pueden ayudar a interpretar un fenómeno que sí parece incontestable, el de la dedicación a las fincas urbanas por parte de los eclesiásticos valencianos desde la segunda mitad del siglo XVIII. Dedicación que, impulsada por la continuidad en la elevación de los precios de arriendo se mantiene, cuando no afecta la desamortización, durante al menos la primera mitad del XIX, ejemplificando acaso actitudes más generales. 


\section{NOTAS}

(1) «Evolución de la renta urbana en la Ciudad de Valencia. 1700-1850. Una primera aproximación".

(2) Los ejemplos aportados son ya múltiples. Como trabajos dedicados al problema y que referencian la mayor parte de casos documentados, F. ANDRÉS ROBRES, Crédito, señorío y propiedad en la Valencia Moderna, Tesis doctoral, Valencia, 1984, y M. PESET REIG y V. GRAULLERA, «Els censals i la propietat de la terra al segle XVIII Valencià», Recerques 18 (1986).

(3) Actitudes económicas de la clerecia culta en el Antiguo Régimen. Política financiera del Real Colegio de Corpus Christi de Valencia. 1583-1810, Valencia, 1986. "Las finanzas del Real Colegio de Corpus Christi ante la desamortización. 1790-1860», Estudis d'Història Contemporània del País Valencià, 6 (1987).

(4) Fuentes, Actitudes..., pp. 188, 218 y 250, y «Las finanzas del Real Colegio...», art. cit., para la década 1841-50. Por supuesto que todos los aspectos relacionados con la evolución patrimonial y rentista de la institución pueden consultarse muy ampliados en los dos trabajos citados. Allí también se hallará referencia de la documentación original de donde emana la información.

(5) Insisto en el calificativo de rentas patrimoniales porque la Fundación tiene otros ingresos tanto ordinarios como extraordinarios procedentes de fuentes distintas a lo que es su hacienda propiamente dicha. Ver Actitudes...

(6) Mismas fuentes que en nota 4.

(7) Las casas desamortizadas pertenecen en realidad a fundaciones de obras pías que, al contrario que la mayoría, han sido incorporadas ( $\mathrm{y}$ así se llaman, administraciones incorporadas) al patrimonio de la Fundación. También influye en el descenso rentista la negativa coyuntura que deriva de la Guerra de Independencia, y que afecta a la cotización de los arriendos. Ver «Evolución de la renta urbana...", art. cit.

(8) Consigue el Colegio evitar anteriores intentos invocando ante la justicia su condición de obra benéfica y educativa. A. Pons prepara en la actualidad un estudio sobre ese tema.

(9) Es el caso de la década 1861-70. En curso ya el proceso desamortizador, al final del decenio sólo quedan al Colegio 39 casas, que deben rendir, como se aprecia, 2.582 libras/año. Así las cosas, parecen exagerados esos ingresos reales medios, próximos a las 5.000 libras. Posiblemente, al procederse a la venta de las casas en subasta, se satisfaciera al Colegio de todos los atrasos acumulados en alquileres anteriores - no podemos confirmarlo-, alterando en consecuencia la imagen de la evolución rentista real. Ese dato, por tanto, acaso deba ser despreciado.

(10) «Las finanzas del Real Colegio...», art. cit.

(11) Actitudes..., Conclusiones.

(12) Se trata de arrendamientos concedidos por el propio Real Colegio, cuya elaboración hemos realizado también personalmente. Expresa la curva el índice compuesto de 10 evoluciones de series individuales. Puede consultarse el método seguido en su confección en Crédito y propiedad de la tierra en el País Valencia. 1610-1810, Valencia, 1987. Las series se reproducen en la tesis doctoral antes citada.

(13) Como en el caso de las tierras, cada curva es la resultante de varias evoluciones particulares, elaborada siempre mediante el método de índices compuestos. Once series integra la curva del Real Colegio, por 5 la de San Miguel. Éstas proceden más exactamente de casas que pertenecen a una fundación de obras pías y vitalicios legada por el Dr. D. Francisco Espejo y administrada por la parroquia. La homogeneidad de que hablamos está en función de la ubicación y calidad de las viviendas respectivas. Las casas de San Miguel se ubican todas en una misma calle - La Mola - de 
un barrio eminentemente popular, y son todas, claro, modestas relativamente (alquileres entre 16 y 20 libras anuales en 1800). Las del Colegio, sitas en calles próximas a la Fundación (Nave, Carnicols, Cruz Nueva, Comedias, Plaza Patriarca), se cotizan más: entre 25-50 libras/año aproximadamente. Al respecto, para mayor detalle, «Evolución de la renta urbana...» art. cit.

(14) Elaborada a partir de los datos de J. M. PALOP, «El producto diezmal valenciano. S. XVII-XVIII. Aproximación a su estudio», en J. GOY y E. LE ROY LADURIE (eds.), Prestations paysannes, dîmes, rente foncière et mouvement de la production agricole a l'èpoque preindustrielle, París-La Haya, 1982.

(15) Afecta la irregularidad sobre todo a la muestra del Colegio. En la explicación, seguramente, las condiciones de habitabilidad-conservación de cada inmueble. Ver «Evolución de la renta urbana...», art. cit.

(16) La impresión de que el alza prosigue ya bien entrado el XIX no procede exclusivamente de las series del Colegio aquí analizadas. Muchas otras evoluciones documentadas la confirman. Pueden verse en «Evolución de la renta urbana...», art. cit.

(17) Ver «Evolución de la renta urbana...», art. cit.

(18) Archivo del Reino de Valencia (A.R.V.), Clero, libro n. ${ }^{\circ} 2429$. Adviértase que el lapso de tiempo es relativamente breve.

(19) Fuentes: A.R.V, Clero, libros n. ${ }^{\circ} 1860$ (San Miguel), 552, 895 y 921 (Santo Domingo), 2495 (Santa Úrsula) y 436 y 3554 (La Merced).

(20) A.R.V., Clero, libro n. ${ }^{\circ} 2495$, fol. 104.

(21) A.R.V., Clero, libro n. ${ }^{\circ} 1860$, fols. $417-418$

(22) A.R.V., Clero, libros n. ${ }^{\circ} 895$ y 921.

(23) Por ejemplo, en la década 1811-20, levanta de nueva planta dos edificios en la calle Corregería por un importe elevado: alrededor de 8.500 libras. Ver «Las finanzas del Real Colegio...», art. cit.

(24) Actitudes..., pág. 91.

(25) Archivo del Colegio de Corpus Christi, Sindicado de administraciones, 1792, pág. 156.

(26) Podemos ofrecer algunos datos al respecto: en 1740, las administraciones separadas del real Colegio alquilan 21 casas, por importe de 648 libras, el $12 \%$ de su ingreso global. en 1800 son ya 114 viviendas y 4.014 libras, el $27 \%$. Es cierto que la trayectoria depende más de la incorporación de nuevas fundaciones que del desarrollo de las ya existentes, pero eso no resta en absoluto, más bien al contrario, representatividad a los datos: los bienes de las nuevas administraciones no hacen sino reflejar las preferencias rentistas de los sectores sociales pudientes. Ver Actitudes..., pp. 280-282.

(27) Ver Crédito y propiedad de la tierra..., pp. 160-199. Para el caso concreto del Colegio, Actitudes, pp. 202-205.

(28) Debe tenerse en cuenta, ya se dice allí, que los datos de renta teórica se ofrecen para el año final de cada década, por lo que siempre habrán diferencias a su favor. La renta esperable en 1771 podría ser muy inferior a la de 1780 cuando en el período el patrimonio se había incrementado considerablemente. Con esa advertencia, es fácil deducir que los ingresos reales se acercan siempre al $100 \%$ de los posibles.

(29) Actitudes..., apéndice gráfico.

(30) Encontramos serios endeudamientos, p. ej., en el período 1805-21, protagonizados por arrendatarios de Santa Úrsula y El Carmen. Este último convento perdona por ejemplo deudas a M. ${ }^{a}$ Teresa Moreno en atención a que la dicha era pobre de solemnidad y no hay esperanza de poder cobrar, aunque debe abandonar la casa (A.R.V., Clero, libro n. ${ }^{\circ} 2429$, 1805). La documentación de las agustinas es aún más clara: y viendo la absoluta imposibilidad y pobresa del inquilino, no sólo para pagar lo mucho que está debiendo por atrasos, sino también para el alquiler corriente, se tuvo por más conveniente despojarle de la casa como efectivamente se logró aunque con trabajo... (A.R.V., Clero, libro n. ${ }^{\circ} 2495,7 \mathrm{v} ., 1820$ ). Aunque a veces se muestran más firmes con los recalcitrantes. Cierto individuo, no quiere saber nada. Yo hice salir a su suegra y pude sacar de otra compañera inquilina en varios pagos la cantidad de 120 reales de vellón... (Ibídem, 6v, 1821). También en el Colegio es normal el mismo proceder: perdón de deudas pero recuperación del inmueble.

(31) Crédito y propiedad de la tierra...

(32) Ibidem, pp. 318-328.

(33) Actitudes, pág. 282.

(34) Crédito y propiedad de la tierra..., pp. 267-290. 
(35)

\begin{tabular}{cccccc} 
OBRAS & $\begin{array}{c}\text { IMPORTE } \\
\text { OBRAS } \\
\text { f.S.D. } 1\end{array}$ & $\begin{array}{c}\text { PRECIO } \\
\text { ARRENDAMIENTO } \\
\text { POSTERIOR }\end{array}$ & $\begin{array}{c}\text { PRECIO } \\
\text { ARRENDAMIENTO } \\
\text { ANTERIOR }\end{array}$ & $\begin{array}{c}\text { GANANCIA } \\
\text { NETA } \\
\text { RENA } 2\end{array}$ & $\begin{array}{r}\text { RENTABILIDAD } \\
2 \times 100 / 1\end{array}$ \\
\hline Santa Úrsula .............. & 2.445 .13 .04 & $138 £$ & $24 £$ & $114 £$ & $4,66 \%$ \\
San Miguel Fumeral ... & 2.369 .14 .01 & $150 £$ & $36 £$ & $114 £$ & $4,81 \%$ \\
San Miguel Peixcadors & 1.289 .03 .00 & $102 £$ & $18 £$ & $84 £$ & $6,51 \%$
\end{tabular}

(36) A.R.V., Clero, libro n. ${ }^{\circ} 2495$. De ese precio retuvo el Convento 166 libras, 13 sueldos y 4 dineros para satisfacer un censo de 5 libras de pensión anual al que estaba sujeta la propiedad y del que era acreedor el Convento de Jesús, quedando limpias al vendedor 1.034 libras $16 \mathrm{~s}$ y $8 \mathrm{~d}$; pero el importe sobre el que debe hacerse el cálculo es, claro, el total. 